The Nepali Math. Sc. Report

Vol. 34, No. 1 and 2, 2016

\title{
MODELING OF INDOOR AIR FLOW DISTRIBUTION IN A NATURALLY VENTILATED KITCHEN
}

\author{
BUDDHI P. SAPKOTA ${ }^{1}$, KEDAR N. UPRETY ${ }^{2}$, HARIHAR KHANAL ${ }^{3}$ AND \\ PRAKASH V. BHAVE ${ }^{4}$ \\ ${ }^{1}$ Ratna Rajyalaxmi Campus, Tribhuvan University, Kathmandu, Nepal \\ buddhisapkota@gmail.com \\ ${ }^{2}$ Central Department of Mathematics, Tribhuvan University, Kirtipur, Nepal \\ ${ }^{3}$ Department of Mathematics, Embry-Riddle Aeronautical University, \\ Daytona Beach, FL 32114-3900, U.S.A. \\ harihar.khanal@erau.edu \\ ${ }^{4}$ International Center for Integrated Mountain Development, Kathmandu, Nepal
}

\begin{abstract}
This paper focuses on the modeling of indoor air pollution in a naturally ventilated kitchen based on the computational fluid dynamics (CFD) approach to assess its ventilation effectiveness. The 3D incompressible Navier-Stokes equations with conservation of total energy are solved numerically using ANSYS-Fluent software and the pollutant paths are investigated from the profiles of velocity, pressure, turbulent kinetic energy and temperature throughout different sections of the kitchen. Experimental verification is made through the measurement of indoor air contaminant in the same kitchen. The simulation results agrees well with the on-site measured data.
\end{abstract}

Key Words: Indoor air pollution, Navier-Stokes equation, numerical modeling, natural ventilation

AMS (MOS) Subject Classification. Primary: 65N08; Secondary: 76F60, 476D05.

\section{INTRODUCTION}

Biomass is one of the most important source of indoor air pollution(IAP). Existing studies demonstrate quite clearly that the increased risk of contracting cancer and respiratory symptoms for non-smoking Asian women appears to be associated with certain cooking practices instead of cigarette smoking[4]. The incomplete combustion of biomass releases complex mixture of organic compounds, which include suspended particulate matter, carbon monoxide, carbon dioxide, volatile organic compounds, fine particulate matters and ultrafine particles, poly-organic material, poly-aromatic hydrocarbons, formaldehyde etc.[12]. Carbon Monoxide (CO) is one of the most deadly pollutant and has adverse health effect on human health.

Ventilation of the kitchen needs to be healthy or well-functioning so that the people inside get comfortable environment to breath. It should not allow contaminated air to accumulate and pollutant concentrations to increase which is injurious to the human health

Received June 2, 2016 
especially a large number of women living inside the kitchen most of the time. There are mainly two types of ventilations which are mechanical and natural. Natural ventilation of buildings is an important approach towards a sustainable and energy-efficient built environment. Natural ventilation can be driven by wind-induced pressure differences or by thermally-induced pressure differences, or by a combination of both (e.g. Linden 1999, Hunt and Linden 1999, Li and Delsante 2001, Heiselberg et al. 2004, Larsen and Heiselberg 2008, Chen 2009, Van Hooff and Blocken[10]. Apart from these driving forces, natural ventilation requires the presence of sufficiently large ventilation openings between the outdoor and indoor environment[1].

Considerable progress has been made recently in developing mathematical models for predicting pollutant concentration in air[5]. Numerical methods involves replacing the partial differential equations with discretized algebraic equations. These equations are then numerically solved to obtain flow field values at the discrete points in space and time. Compared to the full scale experiments, the computational fluid dynamics method is inexpensive and alternative in indoor design, optimum and pollutant dispersion for health and safety reasons [4] [9]. Turk purposed a general equation for calculating concentration in a chamber that included both exterior and interior source and the removal effect of pollutants by air treatment system in 1963. Jones and Fagon used Turkes equation to calculate carbon monoxide (CO) concentration from cigarette smoke in 1974. In 1974 Nielson used numerical predictions of indoor airflow and worked mainly on two-dimensional, steady and isothermal flows. Even though his two-dimensional results are not very useful for engineering applications, the methods he used showed a very strong potential for solving practical air flow problems in a room. Many researchers validated their computational results with experiments, including Nielson, Sakamoto and Matsuo, and Gosman et al. Lu et al. used computational fluid dynamics(CFD) to simulate airflow/temperature in a room to track pollutant dynamics and found that the CFD results correlated reasonably well with measured experiments. Sinha et al. also used finite volume CFD to compare discrete vent configuration cases, but also ran simulations for different fixed Reynolds number $R e$ and Grashof number $G r$. Freire et al. studied the problem of optimizing thermal comfort and energy savings using model-based predictive control where their controlled input was to apply power to the heating, ventilation and air conditioning (HVAC) device. Ishizu examined experimentally the inclusion of mixing factor into these models and Repace and Lawrey also developed a modification of the Turk equation incorporating a mixing factor. Trynor G. W. et al.[13] studied the effects of ventilation on residential air pollution, due to emission from a gas-fired range in 1982 and showed that the range hood is the effective means of the removing pollutant from gas fired range; removal rates varied from 60 to 87[13]. In 1996 Ott et al. showed theoretically that a mathematical trend correlation term should be incorporated into the time averaged version of the model to make it exact. Neil E. Klepeis[6] studied on validity of the 'uniform mixing' assumption: determining human exposure to environmental tobacco smoke, environmental health perspectives.

Hensen, J.L.M et al.[3] demonstrated as a merit and drawbacks of various computer modeling approaches for HVAC design and performance prediction. He pointed out some 
of the future works including integration of CFD in general building energy simulation for third approach, prediction of thermal comfort as affected by the flow and temperature field within a room. Ott Wayne R.[7] developed a mathematical model for predicting indoor air quality from smoking activity. Chen Q. and Srebric J. in 2000 [2] has developed a new model to assess building shape design, to evaluate effectiveness of natural ventilation in buildings to model volatile organic compound (VOC) emission from building materials and calculated indoor air environment parameter. Fernanda Carmen Fuoco et. al. [10] concluded that diffusion is an important transport mechanism in cross-ventilation of buildings, and that special care is needed to select the right amount of physical diffusion and to reduce the numerical diffusion, by using high-resolution grids and by using at least second-order accurate discretization schemes.

In this paper, we develop a CFD model for indoor pollution in a typical Nepali kitchen using ANSYS-Fluent software and explore on the distribution pattern of the velocity, pressure, contaminants inside a kitchen, and the analysis of flow driven by wind and the buoyancy. The study investigates the dispersion of indoor pollutants in a kitchen under the conditions with change of window positions in the wall near and far from the stove. Measurements of carbon monoxide levels at different locations in the kitchen with different conditions are compared with the simulated results.

Rest of the paper is organized as follows. The mathematical model is described in section $\S 2$ and numerical methods are presented in section $\S 3$. After giving a detailed description of the experimental study in section $\S 4$, the numerical simulation results are presented and discussed in $\S 5$, with conclusions in $\S 6$.

\section{Mathematical Model}

The study of three-dimensional incompressible flow of air as a multi-component fluid includes dry air and contaminants. The fluid properties vary according to ideal gas model and therefore, it accounts for the buoyancy associated to the natural convection of the heated fluids. The mathematical model is based on the Reynolds-Averaged Navier-Stokes equations and associated boundary conditions.

2.1. Geometry of the Model. We consider a typical Nepali kitchen with one door, two windows and a vent with the dimensions as shown in figure 1 . The proposed model kitchen has dimensions of $4.2 \times 3.0 \times 2.7 \mathrm{~m}^{3}$. Here the positions of the windows of similar size $0.4 \mathrm{~m} \times 1.6 \mathrm{~m}$ are situated at a distance of $0.8 \mathrm{~m}$ from each other. The vent of dimension $0.5 \times 0.5 \mathrm{~m}^{2}$ is situated in the side adjacent to windows.

2.2. Governing Equations. The fluid flow is incompressible and turbulent. The following mass, momentum, energy conservation equations with 2-equation $k-\epsilon$ turbulence model with wall functions are used as the governing equations.

$$
\frac{\partial \rho}{\partial t}+\frac{\partial\left(\rho u_{i}\right)}{\partial x_{i}}=0
$$




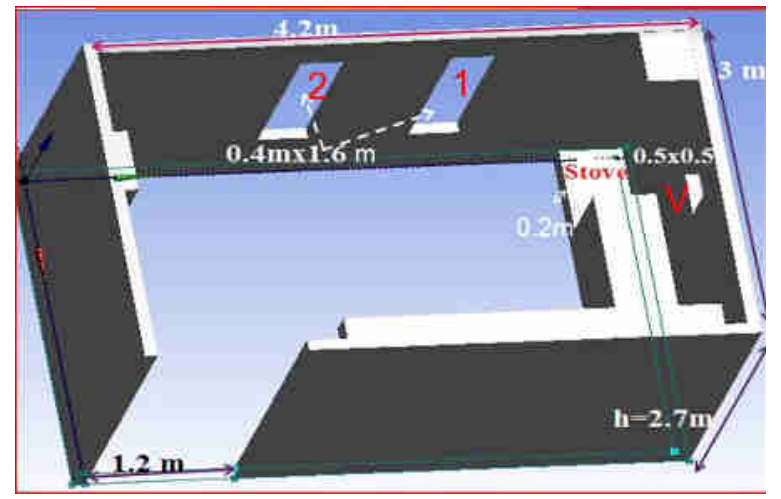

FIGURE 1. Description of a naturally ventilated kitchen

$$
\begin{gathered}
\frac{\partial\left(\rho u_{i}\right)}{\partial t}+\frac{\partial\left(\rho u_{i} u_{j}\right)}{\partial x_{j}}=-\frac{\partial p}{\partial x}+\frac{\partial}{\partial x_{j}}\left[\mu\left(\frac{\partial u_{i}}{\partial x_{j}}+\frac{\partial u_{j}}{\partial x_{i}}\right)\right]+\rho g_{i} \\
\frac{\partial(\rho H)}{\partial t}+\frac{\partial\left(\rho u_{i} H\right)}{\partial x_{i}}=\frac{\partial}{\partial x_{i}}\left[\frac{k}{c_{p}} \frac{\partial H}{\partial x_{i}}\right]+S_{H}
\end{gathered}
$$

where, $u_{i}$ is the velocity $(m / s)$ component $(u, v, w), p(P a)$ is the pressure, $H\left(W / m^{2} . K\right)$ the enthalpy and $S_{H}$ a source term. The diffusion term is indicated by the kinematic viscosity $\mu(\mathrm{kg} / \mathrm{m} . \mathrm{s})$, the thermal conductivity $k(\mathrm{~W} / \mathrm{m} . K)$ and the specific heat $c_{p}(\mathrm{~J} / \mathrm{kg} . K)$. The time is indicated with $t, x_{i}$ is the coordinate axis $(x, y, z), \rho\left(k g / \mathrm{m}^{3}\right)$ is the density and $g_{i}$ $\left(\mathrm{m} / \mathrm{s}^{2}\right)$ is the gravitational acceleration.

For the standard $k-\epsilon$ equation, the transport equations for turbulent quantities are given by:

$$
\begin{gathered}
\frac{\partial(\rho k)}{\partial t}+\frac{\partial}{\partial x_{i}}\left(\rho k u_{i}\right)=\frac{\partial}{\partial x_{j}}\left[\frac{\mu_{t}}{\sigma_{k}} \frac{\partial k}{\partial x_{j}}\right]+2 \mu_{t} S_{i j} . S_{i j}-\rho \epsilon \\
\frac{\partial(\rho \epsilon)}{\partial t}+\frac{\partial}{\partial x_{i}}\left(\rho \epsilon u_{i}\right)=\frac{\partial}{\partial x_{j}}\left[\frac{\mu_{t}}{\sigma_{\epsilon}} \frac{\partial \epsilon}{\partial x_{j}}\right]+C_{1 \epsilon} \frac{\epsilon}{k} 2 \mu_{t} S_{i j} . S_{i j}-C_{2 \epsilon} \rho \frac{\epsilon^{2}}{k}
\end{gathered}
$$

where eddy viscosity $\mu_{t}=\rho C_{\mu} \frac{k^{2}}{\epsilon}$, component of rate of deformation $S_{i j}=\frac{1}{2}\left[\frac{\partial u_{i}}{\partial x_{j}}+\frac{\partial u_{j}}{\partial x_{i}}\right]$ with $C_{\mu}=0.09$, Prandtl numbers $\sigma_{k}=1$ and $\sigma_{1 \epsilon}=1.3, C_{1 \epsilon}=1.44, C_{2 \epsilon}=1.92$.

2.3. Boundary Conditions. The governing equations are closed with appropriate thermofluid boundary conditions at all the boundaries such as air inlets, outlets, heat flux and wall surfaces. Window- 1 and window- 2 are taken as the velocity inlets and door is taken as the pressure outlet as per the wind direction. At the inlet an inlet velocity is specified. Pressure outlet is used in the outlets, where the pressure at the outlet is taken as ambient pressure. As a fluid particle grows in proximity to a rigid wall, the greater will be the influence of shear forces from the wall so that in the limit, the velocity will theoretically be zero. The boundary condition on the surface is assumed to have zero relative velocity between the surface and gas, which is the no-slip condition. Since the surface is stationary, with the flow passed it, $u=u_{\text {wall }}=0$ i.e. $u=v=w=0$ at the solid walls. Wall functions are used 
at walls. The temperature $T$ of the fluid layer immediately in contact with the surface is equal to the material temperature $T_{w}$ at the surface i.e. $T=T_{\text {wall }}$ (at wall). Since the wall is non-porous, there is no mass flow into and out of the wall. So temperature flux at the solid wall is taken as zero.

\section{NumericAl Method}

3.1. Discretization. The computational domain (geometry of the kitchen described in figure 1) is generated with ANSYS software using the inbuilt design and mesh modeling section. The indoor space of the model is discretized into non-uniform computational cells with unstructured hexahedral mesh. We have avoided tetrahedral and pyramid cells, which can have negative effects in terms of numerical diffusion and convergence with higher-order discretization schemes[1].

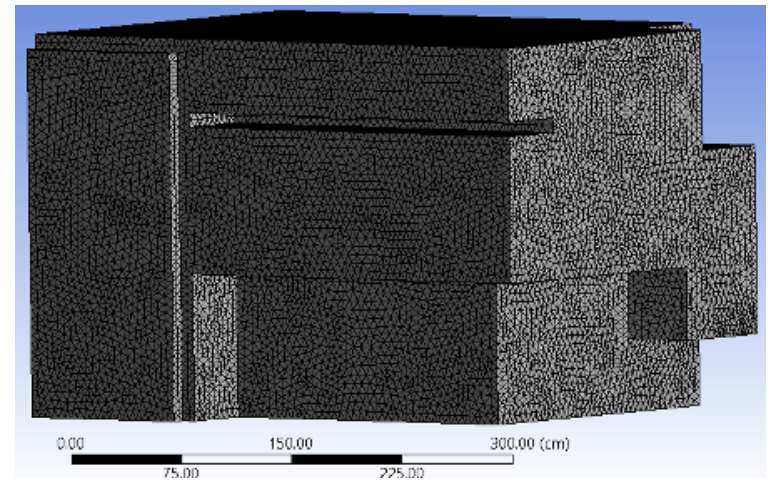

FigurE 2. Discretization of the kitchen (interior/fluid part)

The governing equations (2.1) - (??) are discretized using the finite volume method (FVM) on a spatially rectangular computational mesh refined locally at the specified fluid regions where high gradients are expected. The FVM grants a conservative discretization of the governing equations, with spatial derivatives (fluxes) approximated with secondorder upwind scheme. Pressure based solver with Semi-Implicit Pressure Linked Equations (SIMPLE) algorithm [8] is used for pressure velocity coupling. Resulting system of linear algebraic equations is solved by iterative method.

The values of velocity, temperature, kinetic energy, dissipation rate of kinetic energy are set at the boundaries. Least square cell-based method is used for the interpolation of field variables stored at cell centers to the faces of control volumes. Second order schemes are used for the pressure, momentum, turbulent kinetic energy and turbulent dissipation of kinetic energy. Default values are taken as the under relaxation factors. Gauss-Seidel method is used for smoothing the grids discretized.

3.2. Simulation Setup. In the simulation reported here, we employ a fairly fine nonuniform grid consisting of 117662 nodes and 641942 elements. Finer grids were tested, with no discernible effect (to at least 3 significant digits). Inlet velocity of $0.2 \mathrm{~m} / \mathrm{s}$ is taken as the velocity inlet boundary conditions. No slip conditions for momentum and zero flux for 
thermal boundary condition are used. The room temperature of $300 K$ is used in the room as temperature boundary. The operating pressure of $101325 \mathrm{~Pa}$ is used with air density $1.225 \mathrm{~kg} / \mathrm{m}^{3}$. Using the time step size of 0.1 seconds with maximum 20 iterations per time step for the iterative solvers, the simulations were carried out up to time $t_{\max }=822$ seconds. It took approximately 30 hours to complete the simulation in Intel i7-4600U CPU @ $2.10 \mathrm{GHz} \times 4,8 \mathrm{~GB}$ RAM computer.

\section{Experimental Study}

The measurement of indoor air contaminants in a room was done in Chitwan, Nepal. Figure 3 shows description of the kitchen for experimental setup. Continued data for two and half days was recorded. The main instruments used for the study were 1) Micro-AethAE51 for measuring Black Carbon, 2) IAQ Probe to measure $\mathrm{CO}_{2}$, CO, relative humidity, temperature, VOC and 3) Aerocet-831 to measure the particulate matters $P M_{1}, P M_{2.5}$, $P M_{4}, P M_{10}$ and total suspended particles (TSP).

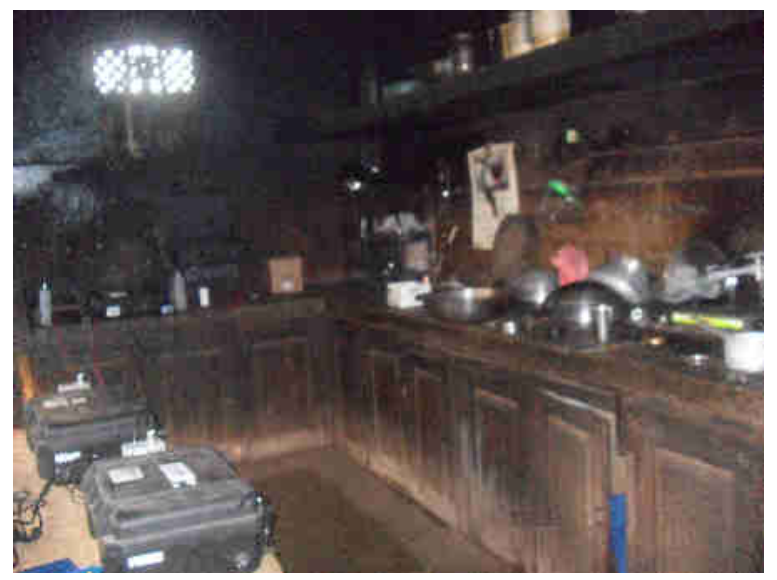

FiguRE 3. Experimental setup in the kitchen

Five different sampling locations in the room, as shown in figure 4, were used for the measurement of these pollutants. Three sets were kept in each of the five locations A, B, C, $\mathrm{D}$ and $\mathrm{E}$. Set $\mathrm{A}$ was near the vent at the level of $1.7 \mathrm{~m}$ from the ground, set-B was adjacent to stove 0.9 meter above and right of the stove level, two of the sets $\mathrm{C}$ and $\mathrm{D}$ were in the breathing zone/dining area and the fifth set $\mathrm{E}$ was in the corner of the room at a height of $2.4 m$ in the opposite side of the location of stove.

History of carbon monoxide concentration at various sample locations inside the room under different conditions (opening and closing of windows 1, 2 and the vent) are plotted and displayed in the figures 5 - 9 .

Figure 5 shows the distribution of $\mathrm{CO}$ when window- 1 is open and vent is open. The concentration at position $\mathrm{A}$ is the highest. The concentration at location $\mathrm{B}$ is lower than concentration of $\mathrm{C}$ and $\mathrm{D}$. The average of $\mathrm{CO}$ concentration at $\mathrm{B}, \mathrm{C}$ and $\mathrm{D}$ is $16 \mathrm{ppm}$ whereas the concentration at $\mathrm{A}$ is found to be $91 \mathrm{ppm}$ during the time period of 7:30 to 9:10. 


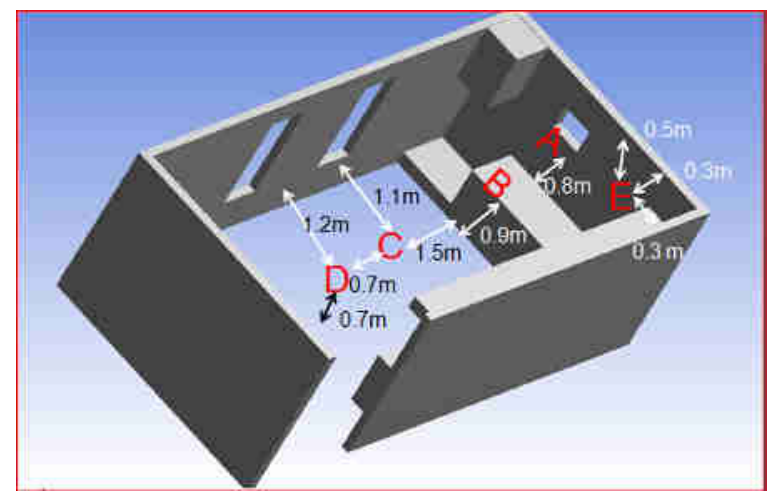

FIgURE 4. Sampling Locations

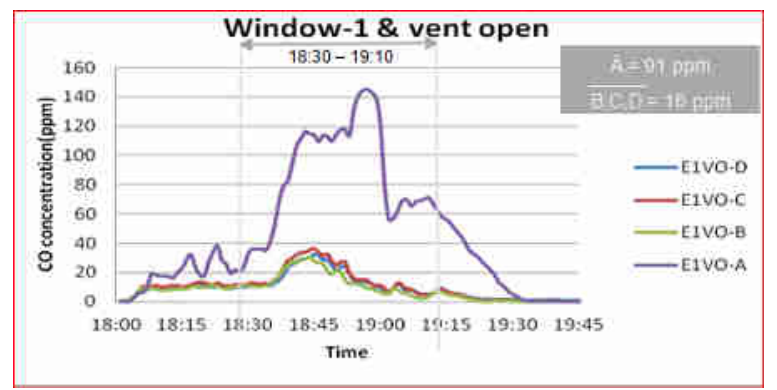

Figure 5. CO distribution at A, B, C, D when window-1 and vent is open

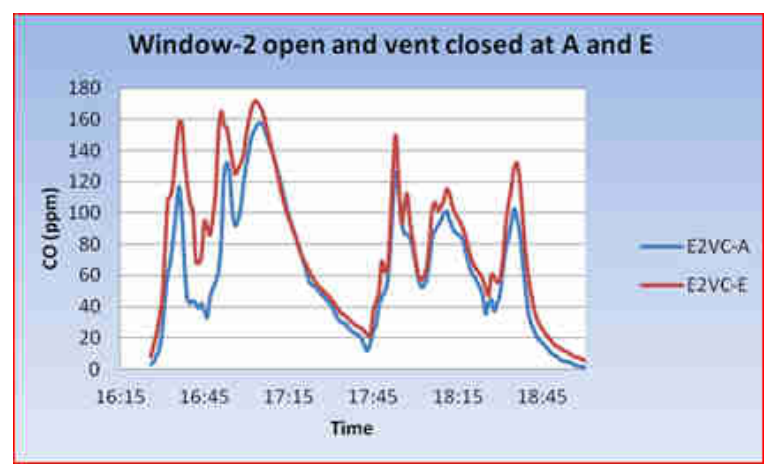

Figure 6. CO distribution at $\mathrm{A}$ and $\mathrm{E}$ when window-1 and vent is closed

Figure 6 shows that the concentration at $\mathrm{E}$ is slightly higher than at A. Opening of window-1 significantly decreases the concentration at B than that of opening of window-2.

When the window-2 is open the concentration goes higher at B than at C and D as can be seen in figure 8 . When vent and window-2 both are open as in figure 9 , the concentration at $\mathrm{B}$ increases and the concentrations at $\mathrm{D}$ is decreased significantly. The concentration of dining region $\mathrm{C}$ also increases. This condition gets very less volume for mixing of indoor air pollution with the fresh air from window-2 as a result, more region in the room gets higher concentration.

From the experimental study we found that the concentration of carbon monoxide at location $\mathrm{A}$ is about 3-5 times higher than at B, C, D for all cooking events. Exposure is 


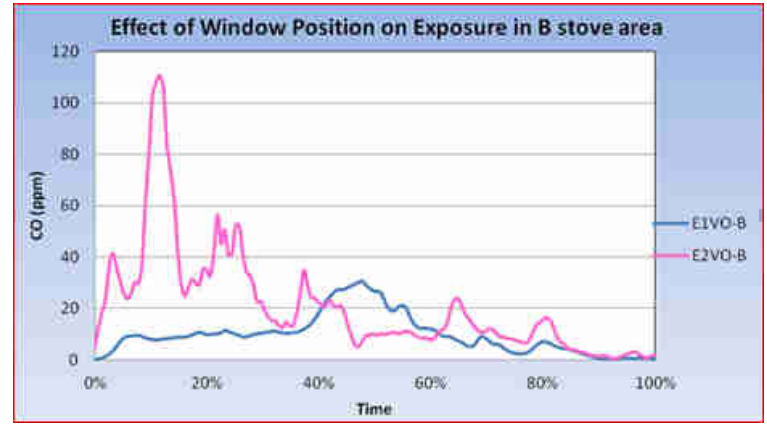

FiguRE 7. Opening of window-1 decreases the concentration at B

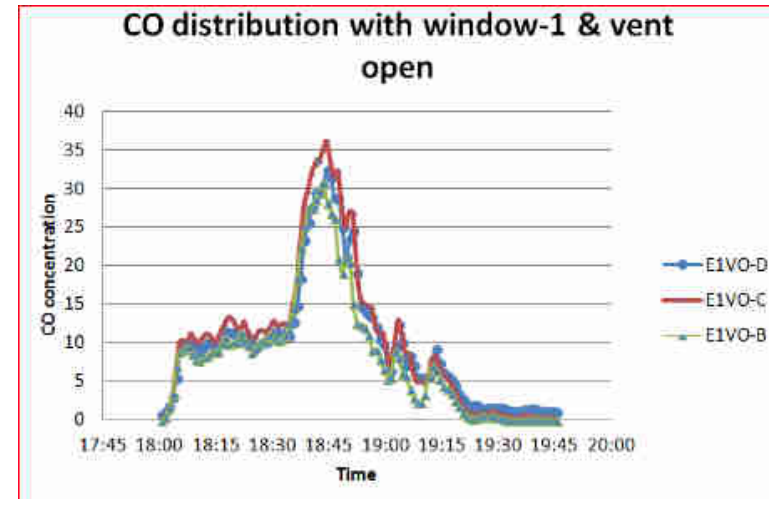

FiguRE 8. Concentration when window-1 and vent open

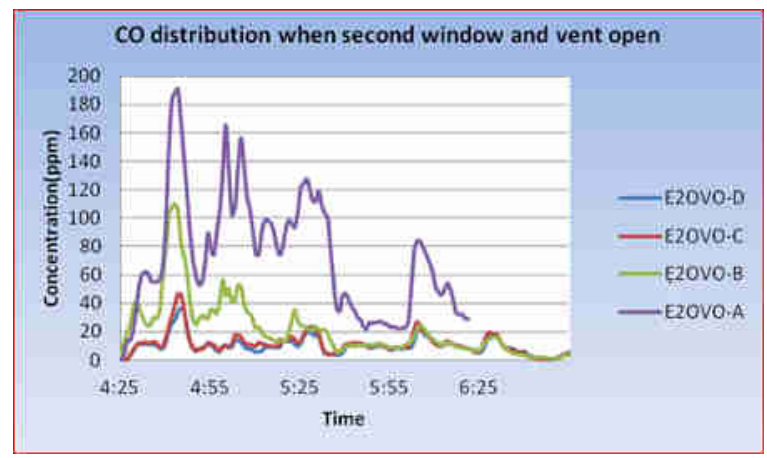

Figure 9. Concentration when window-2 and vent open

highest for occupants standing at A near the stove. Opening window-1 (instead of window2 ) affects the $\mathrm{CO}$ distribution in two ways. It reduces concentrations near the stove at $\mathrm{B}$; increases concentration in the dining area $\mathrm{C}$ and $\mathrm{D}$. Opening or closing of vent does not have much effect on the concentration perhaps because vent is very small compared to the window. Above conclusions also apply to $\mathrm{BC}, P M_{2.5}$, and total volatile organic compounds(TVOCs).

\section{Results And Discussions}

The numerical simulations are used to analyze the fluid flow parameters such as velocity, pressure, temperature turbulence with the window positions in the kitchen. Additional 
planes are created at different locations especially at $1.1 \mathrm{~m}, 2 \mathrm{~m}$ and $2.4 \mathrm{~m}$. The first plane is at the height of occupant's breathing zone, second plane is at the height of $2 \mathrm{~m}$ which is the height of the occupant. Measuring instruments are placed in the level of these planes. Volume renderings and surface flow distribution analysis on different planes are generated and studied to find the flow distribution patterns.

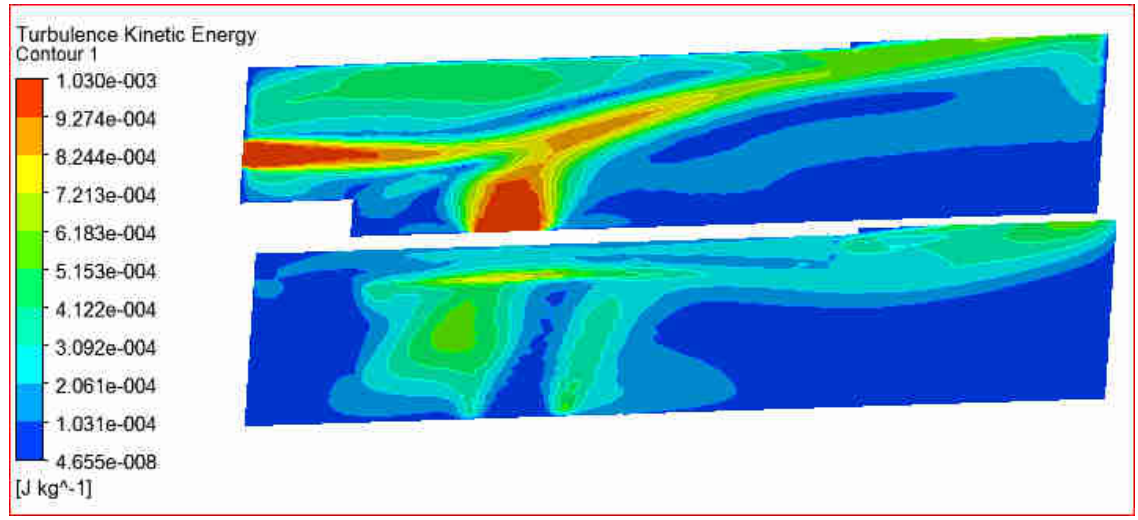

Figure 10. Trubulent kinetic energy above $1.1 \mathrm{~m}$ when window-1 and vent are open

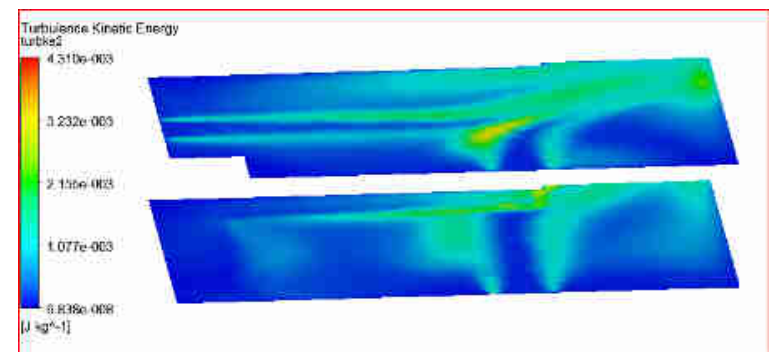

Figure 11. Turbulent kinetic energy at $1.1 m$ and $2 m$ when window- 2 and vent open

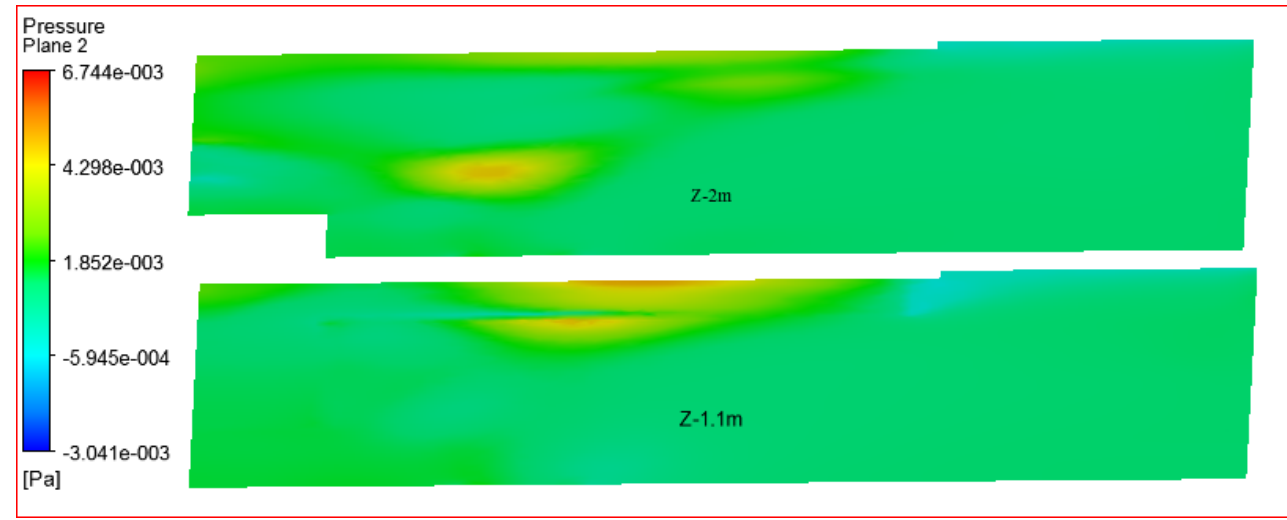

Figure 12. Pressure distribution at $1.1 m, 2 m$ from ground with Window-1 and vent open

Figures 10 and 11 respectively show turbulence of the fluid flow when window- 1 and window-2 are open. The flow is turbulent in two sides of the flow path from window-2 
towards door, turbulence is observed at opposite to wall and door. Small turbulence is also observed in the slabs just above the level of stove and in wall. Figure 11 indicates the turbulence of air flow at $1.1 \mathrm{~m}$ at $2 \mathrm{~m}$ above the ground which shows greater turbulence contributed from the vent and the window. The plane at $2 \mathrm{~m}$ has larger turbulence in fluid flow than that of the plane at $1.1 \mathrm{~m}$. Figure 12 shows the pressure distribution in the kitchen. Distribution of pressure in the room is normal. Slightly higher pressure in the opposite side of the kitchen.

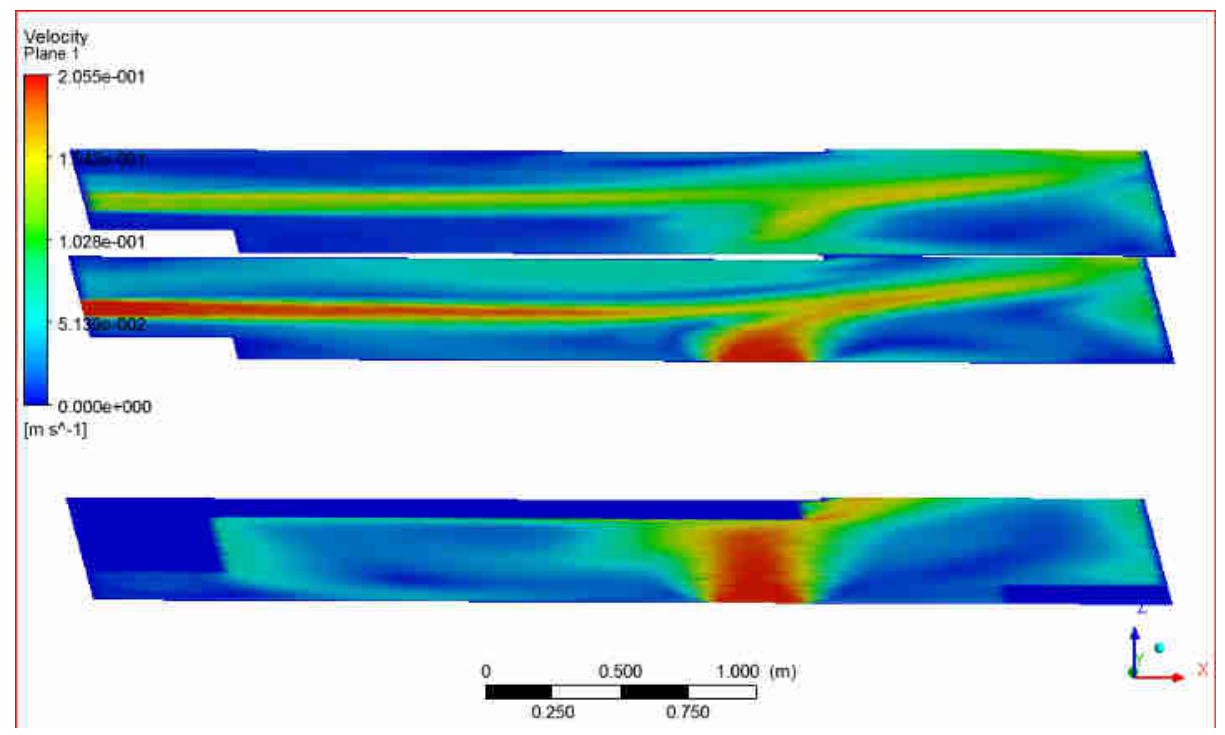

FIGURE 13. Velocity distribution at $1.1 m, 2 m$ and $2.4 m$ from ground with window-2 and vent open

Figure 13 shows the distribution of the velocity at $1.1 \mathrm{~m}, 2 \mathrm{~m}$ and $2.4 \mathrm{~m}$ above the ground. The plane at $1 \mathrm{~m}$ shows the higher velocity in path of the fluid from window-2 and moves towards the opposite wall and door. Slightly higher velocities are observed in the corners of the slabs. In the plane at height of $2 m$ shows the higher velocity in the flow path from vent and window-2 and near the opposite wall. In the top plane the velocity gradually decreases and velocity near wall are also low.

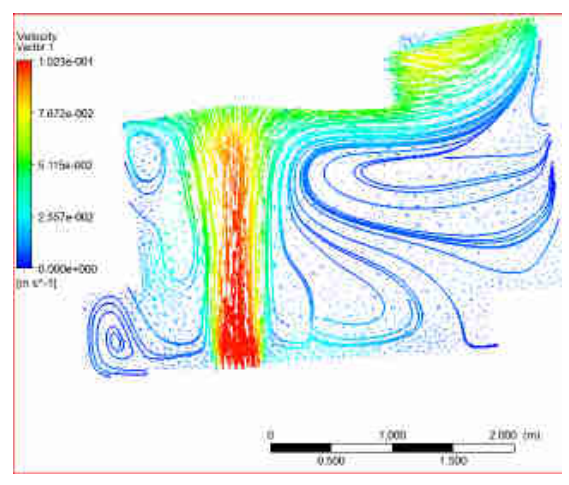

Figure 14. Velocity streamlines at $1.1 m$ (left) and at $2 m$ (right) with window-1 and vent open

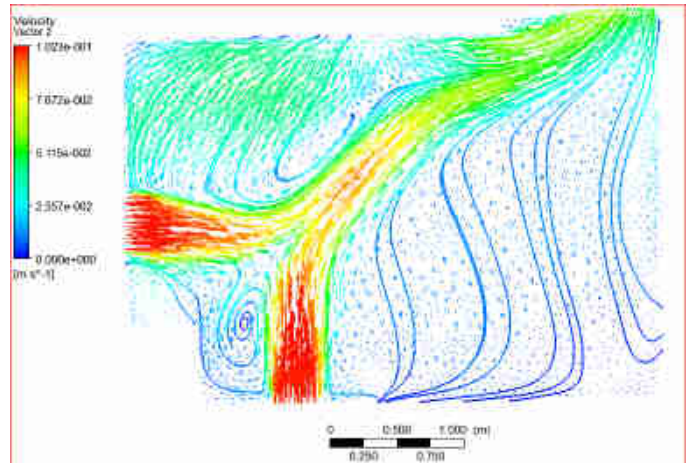


Velocity streamlines on the planes at $1.1 \mathrm{~m}$ and $2 \mathrm{~m}$ are shown in figure 15 and figure 14 for the case of window 1 and window 2 open respectively. The formation of vortex at the height of $1 \mathrm{~m}$ in the side of stove can be seen in figure 15 which increases the concentration of pollutants in the location $\mathrm{B}$ and also results in lowering the concentration in $\mathrm{D}$ area as also observed in the measured results plotted in figure 9 . Thus, opening of window-2 instead of window- 1 increases the concentration of pollutants in the area where occupant stays which is near to location $\mathrm{B}$.
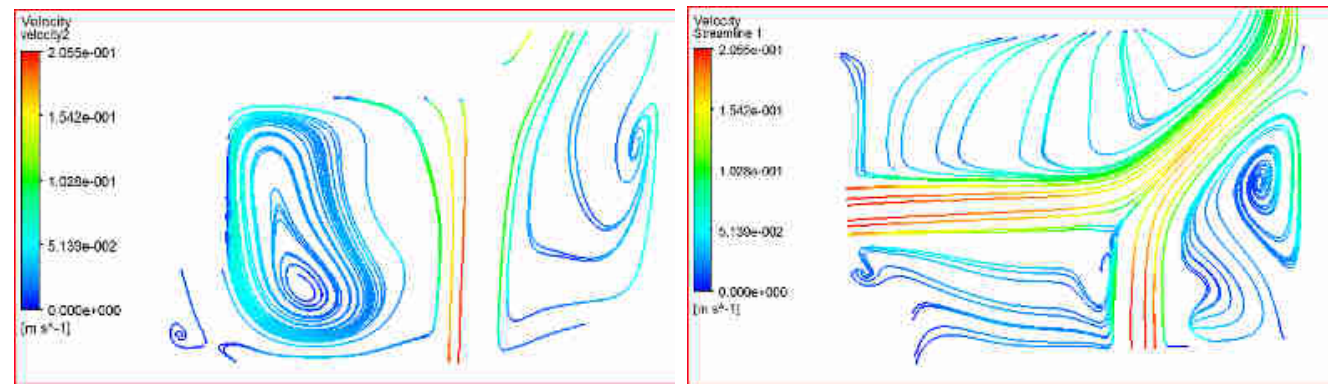

Figure 15. Velocity streamlines at $1.1 m$ (left) and at $2 m$ (right) with window-2 and vent open

It is explored that the concentrations at the occupant location is higher when the window in open position is located far from the stove. Simulation and experimental results verify that in such cases the concentration increases significantly near the position of stove. The fresh air from the window dilutes pollutants in the dining region. It is found that the velocity and turbulence are higher near the door and near windows. The vortices are formed in both sides of the path of fluid flow in room from door. Such areas where the air could be trapped should be avoided for the occupant's position in the kitchen. The pressure is observed higher in wall opposite to the door. As seen in the results of the fluid flow, cross ventilated rooms are effective and efficient for indoor air quality.

\section{Conclusions}

We developed a three dimensional time-dependent computational model for indoor air pollution in a kitchen using ANSYS-Fluent software and investigated the dispersion of pollutants under the conditions with change of window positions in the wall near and far from the stove. The computational model is validated comparing the numerical simulations with the on-site measured data of carbon monoxide levels at different location in the kitchen under various conditions. Simulations of up to 15 minutes shows a good agreement with the experimental data. Full-fledged simulations of the model will be very useful for the proper design of an efficient ventilation system in the kitchen which provides better quality of air to the occupants of buildings through effective removal of the pollutants. Due to the intricate geometry of the kitchen, the problem requires very intensive computations demanding high performance computing.

Acknowledgment: The first author (BPS) would like to acknowledge University Grants Commission Nepal for research grant, Indian Institute of Technology Guwahati and Prof. 
Sharad Gokhale for internship with facilities of research, CAD lab and other facilities; and International Centre for Mountain Development (ICIMOD) for IAP measuring instrument support.

\section{REFERENCES}

[1] Blocken B., Gualtieri C., Ten iterative steps for model development and evaluation applied to Computational Fluid Dynamics for Environmental Fluid Mechanics, Environmental Modeling 6 Software 33: $1-22,2012$.

[2] Chen Q., Srebric J., Application of CFD tools for Indoor and Outdoor Environment Design, International Journal on Architectural Science, Vol. 1, No. 1, Building Technology Program Department of Architecture, Massachusetts Institute of Technology 77 Massachusetts Avenue, USA, pp. 14-29, 2000.

[3] Hensen M. J. L., Hamelinck M. J. H., Loomans M. G. C., Modeling approaches for displacement ventilation in offices, Proceeding of the 5th international conference Room vent '96, July, Yohohama: University of Tokyo, pp. 1-8, 1996.

[4] Jiaqing Zhou, Chang Nyung Kim, Numerical investigation of indoor $\mathrm{CO}_{2}$ concentration distribution in an apartment, 3rd International Symposium on Sustainable Healthy Buildings, Seoul, Korea, 2010.

[5] N. W. William, Mathematical Modeling and Control of Pollutant Dynamics in Indoor Air, Pasadinia California, California Institute of Technology, pp. 16, 1989.

[6] Neil E. Klepeis, Validity of the Uniform Mixing Assumption: Determining Human Exposure to Environmental Tobacco Smoke, Environmental Health Perspectives, Vol. 107, pp. 357-363, 1999.

[7] Ott Wayne R., Mathematical Models for Predicting Indoor Air Quality from Smoking Activity, Environmental Health Perspectives vol. 107, Supplement 2, Stanford University, California, pp. 375, 1999.

[8] S. V. Patnakar, Numerical Heat Transfer and Fluid Flow, Replica Press, India, 2011.

[9] Posner J.D., Buchanan C.R, Dun-Rankin D, Measurement and Prediction of Indoor Air Flow in a Model Room, Energy and Building Elsevier USA, Vol 35, pp 515-526, 2003.

[10] Ramponi R, Blocken B., CFD Simulation of Cross-ventilation Flow for Different Isolated Building Configurations: Validation with Wind Tunnel Measurements and Analysis of Physical and Numerical Diffusion Effects, Journal of Wind Engineering and Industrial Aerodynamics 104-106: 408-418, 2012.

[11] Sparks, L.E; Indoor Quality Modeling, Indoor Air Quality Hand Book, The McGraw-Hill Companies, USA, pp. 58, 2004.

[12] J. C. Stratton, B.C. Singer, Addressing kitchen contaminants for healthy, low-energy, Environmental Energy Technologies Division, Lawrence Berkeley National Laboratories Berkeley, USA, 2014.

[13] G. W. Trynor, M. G. Apte, J.F. Dillworth, C. D. Holowwell, A. M. Sterling, Effects of ventilation on residential air pollution, due to emission from a gas-fired range, Environmental International Vol. 8, USA, pp. 447-452, 1982.

[14] H.K. Versteeg, W. Malalasekera, An Introduction to Computational Fluid Dynamics, Pearson Education Ltd, England, 2007. 